Article

\title{
A Semi-Parametric Geographically Weighted Regression Approach to Exploring Driving Factors of Fractional Vegetation Cover: A Case Study of Guangdong
}

\author{
Yuhao Jin ${ }^{1}$, Han Zhang ${ }^{2}$, Yuchao Yan ${ }^{3}$ and Peitong Cong ${ }^{1, *}$ \\ 1 College of Water Conservancy and Civil Engineering, South China Agricultural University, \\ Guangzhou 510642, China; yuhao.jin@scau.edu.cn \\ 2 Key Lab of Geographic Information Science (Ministry of Education), School of Geographic Sciences, \\ East China Normal University, Shanghai 200241, China; zhanghan@geo.ecnu.edu.cn \\ 3 Sino-French Institute for Earth System Science, College of Urban and Environmental Sciences, \\ Peking University, Beijing 100871, China; 13484603157@163.com \\ * Correspondence: slxyky@scau.edu.cn
}

Received: 29 July 2020; Accepted: 7 September 2020; Published: 11 September 2020

check for updates

\begin{abstract}
Ecological degradation caused by rapid urbanisation has presented great challenges in southern China. Fractional vegetation cover (FVC) has long been the most common and sensitive index to describe vegetation growth and to monitor vegetation degradation. However, most of the studies have failed to adequately explore the complexity of the relationship between fractional vegetation cover (FVC) and impact factors. In this research, we first constructed a Semi-parametric Geographically Weighted Regression (SGWR) model to analyse both the stationary and nonstationary spatial relationships between FVC and driving factors in Guangdong province in southern China on a county level. Then, climate, topographic, land cover, and socio-economic factors were introduced into the model to distinguish impacts on FVC from 2000-2015. Results suggest that the positive and negative effects of rainfall and elevation coefficients alternated, and local urban land and population estimates indicated a negative association between FVC and the modelled factors in each period. The SGWR FVC make significantly improves performance of the geographically weighted regression and ordinary least squares models, with adjusted $\mathrm{R}^{2}$ higher than 0.78 . The findings of this research demonstrated that, although urbanisation in the Pearl River Delta in Guangdong has encroached on the regional vegetation cover, the total vegetation area remained unchanged with the implementation of protection policies and regulations.
\end{abstract}

Keywords: fractional vegetation cover; geographically weighted regression; multi-driving factors; Google Earth Engine; Guangdong

\section{Introduction}

Vegetation plays an important role in the energy balance and water cycle and biochemical cycles in global climate change studies [1]. Numerous studies demonstrate that vegetation information provides detailed information on global change and has important practical significance for the analysis and evaluation of the regional ecological environment [2-4]. Fractional vegetation cover (FVC) is a significant indicator of vegetation growth and ecological change monitoring and can be expressed by a vegetation index [5-7]. A good understanding of FVC spatiotemporal variations can help explore the results of the combined effects of human activities and climate change. Additionally, knowledge of associated driving factors helps optimise ecological layout and restoration. 
Most research on regional vegetation coverage change and driving factors focuses on the impact of climate factors, which are closely related to vegetation cover [8-10]. Of these, rainfall and temperature are important factors affecting vegetation growth in East Africa [11,12]. Topographic (e.g., elevation and slope) and climate factors are the most basic natural factors in the region and the primary influence on FVC change in China [13,14]. Additionally, FVC is associated with land use and cover (LCC) factors (e.g., deforestation and urban expansion) $[15,16]$. Socio-economic factors significantly impact FVC and primarily include the destruction of the regional ecological environment and deforestation caused by population growth and economic poverty, and the increase of FVC because of the Grain for Green policy $[17,18]$. To better understand the regional FVC with different factors, bivariate-partial correlation analysis and piecewise linear regression were applied to the exploring the relationship between FVC with various climatic and human-induced factors [19]. Formal analytic framework can be used to quantify the contributions of climatic factors and human activities in driving FVC [20]. However, the principal drivers of FVC in Guangdong remain undetermined.

Since the 1990s, a range of laws and regulations, such as the New Law of Land Administration (1998) and The Regulations on Protection of Basic Farmland (1998) have been proposed and implemented to reinforce vegetation protection and management [21,22]. Several major ecological afforestation construction projects, such as the "Grain for Green" program in 1999, were initiated [23,24]. Additionally, the policy of strengthening environmental protection, promoting cleaner production, and reducing consumption in Guangdong province has been further emphasised with the construction of a forest ecological barrier system for urban green space system in the Pearl River Delta [25]. Thus, the regional ecological environment affected by vegetation cover dynamics and driving factors has become a major concern of the Chinese government.

This study quantitatively distinguishes the impacts of climate, topographic, LCC, and socio-economic factors on regional FVC and determines the principal driving factors affecting FVC dynamics. We construct the Semi-parametric Geographically Weighted Regression model (SGWR) of FVC and analyse the spatial stationarity and non-stationarity of the FVC driving factors that effectively explain the complexity of the relationship between FVC change and impact factors. The spatiotemporal dynamics of vegetation cover are also explored from 2000 to 2015 in Guangdong province at the county level-the third-level administrative division of the study area following provincial (first) and prefectural (second) levels.

\section{Study Area and Data Source}

\subsection{Study Area}

Southern China has more abundant and varied vegetation than any other area in the country. Vegetation cover in southern China has changed with rapid population growth and global climate change. The study area, Guangdong province, is located in the southernmost part of the Chinese mainland and covers an area of approximately $179,800 \mathrm{~km}^{2}$ (Figure 1). By the end of 2015, the resident provincial population 108.49 million was the highest in southern China.

The study area is located at a low latitude with elevated terrain in the north and lowlands in the south (Figure 1c). Because of its tropical, subtropical monsoon and oceanic climates, the territory has some of the most abundant light, heat, and water resources in China [26]. The annual average temperature varies from $19-24^{\circ} \mathrm{C}$, and the average annual rainfall is $1771 \mathrm{~mm}$. Thus, climate conditions are suitable for vegetation growth [27]. 


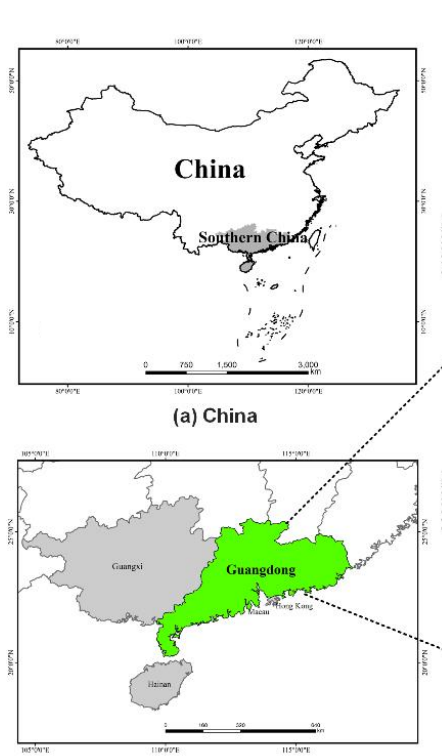

(b) Southern China

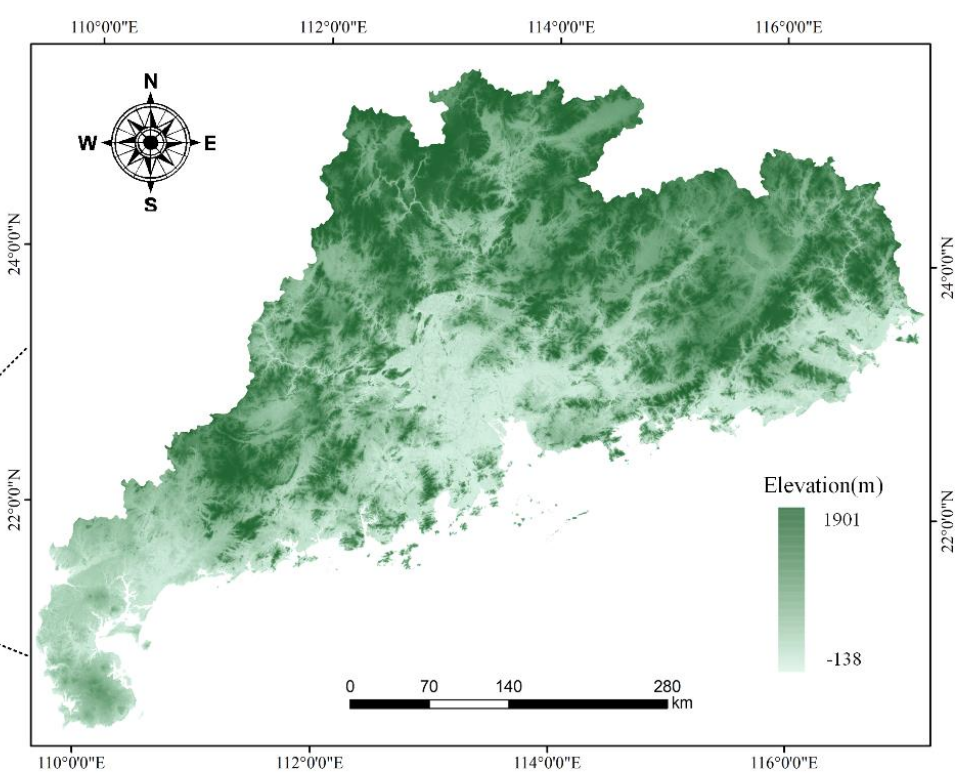

(c) The study area

Figure 1. (a) Location of southern China within China; (b) Location of Guangdong in southern China; (c) Elevation map of the study area.

\subsection{Data}

This paper explores the impact of climate, topography, LCC, and socio-economic factors on FVC. Climate impacts includes rainfall, sunshine duration, temperature, pressure, and humidity, whereas topological variables are elevation, slope, and aspect. Additionally, urban land, water bodies, and unused land were selected as LCC factors. Gross domestic product per capita, income of rural residents, population, gross industrial output value, local fiscal revenue, fixed asset investment, and total retail sales of consumer goods are socio-economic factors related to FVC. Table 1 describes the data sources and variables used in this study.

Google Earth Engine (GEE) makes it available to process a large number of satellite imagery quickly and accurately with planetary-scale analysis capabilities. More than thirty years of historical imagery and scientific datasets are updated and expanded daily in GEE. Vast amounts of dataset derived from The Moderate Resolution Imaging Spectroradiometer (MODIS) can be accessed online based on the GEE platform, which includes The Normalized difference vegetation index (NDVI), Leaf area index (LAI), Gross Primary Productivity (GPP), and other derived datasets. In our study, the NDVI product (MOD13Q1) was selected from 2000-2015 at a 250-m spatial resolution and 16d intervals. These products are computed from atmospherically corrected bi-directional surface reflectances that have been masked for water, clouds, heavy aerosols, and cloud shadows.

Climate change has a direct or indirect impact on vegetation cover. Meteorological data from 26 weather stations in the study area from 2000-2015 were obtained from the Chinese Meteorological Science Data Center, which includes time-series data for rainfall, sunshine duration, temperature, pressure, and humidity (Table 1). In order to fully reflect the impact of climate factors on vegetation coverage, the Inverse Distance Weighting method was used to interpolate the monthly climate data. Then, we calculated the county-level climate factor data set—-derived from the raster of meteorological factors-in Guangdong. The mountainous topography of southern China influences regional vegetation distribution differentiation [28]. We used the Advanced Spaceborne Thermal Emission and Reflection Radiometer Global Digital Elevation Model (ASTER GDEM) to calculate topological data.

Vegetation cover changes as land function caused by land cover dynamics changes. Thus, the information on non-vegetation land was summarised for each county, and included urban land, water bodies, and unused land. The landcover data used in this research cover four years (2000, 2005, 2010, and 2015) and were collected by the Ministry of Land and Resources of China. Compared 
with natural and human factors, socio-economic factors have a significant impact on vegetation cover change at different levels of administrative divisions. The socio-economic factors of each county in this study were primarily selected from the China Statistical Yearbook provided by the National Bureau of statistics; other county data are selected from the statistical yearbook of prefecture level cities from 2000-2015.

Table 1. Data source description.

\begin{tabular}{|c|c|c|c|c|}
\hline Data Name & Factors & $\begin{array}{c}\text { Spatial } \\
\text { Resolution }\end{array}$ & $\begin{array}{l}\text { Temporal } \\
\text { Resolution }\end{array}$ & Data Sources \\
\hline $\begin{array}{l}\text { Vegetation } \\
\text { index }\end{array}$ & $\begin{array}{l}\text { Normalized difference } \\
\text { vegetation index } \\
(\mathrm{NDVI})\end{array}$ & $250 \mathrm{~m}$ & $\begin{array}{l}2000,2005 \\
2010,2015\end{array}$ & $\begin{array}{l}\text { United States Geological Survey } \\
\text { (USGS) } \\
\text { (https://www.usgs.gov/) }\end{array}$ \\
\hline \multirow[t]{9}{*}{ Climate } & Rainfall & $\begin{array}{l}\text { weather } \\
\text { stations }\end{array}$ & $\begin{array}{l}2000,2005 \\
2010,2015\end{array}$ & $\begin{array}{c}\text { Chinese Meteorological Science Data } \\
\text { Center (CMDC) } \\
\text { (http://data.cma.cn/) }\end{array}$ \\
\hline & \multirow{2}{*}{ Sunshine duration } & weather & 2000, 2005 & CMDC \\
\hline & & stations & 2010,2015 & (http://data.cma.cn/) \\
\hline & \multirow{2}{*}{ Temperature } & weather & 2000,2005 & CMDC \\
\hline & & stations & 2010,2015 & (http://data.cma.cn/) \\
\hline & \multirow{2}{*}{ Air pressure } & weather & 2000,2005 & CMDC \\
\hline & & stations & 2010,2015 & (http://data.cma.cn/) \\
\hline & \multirow{2}{*}{ Humidity } & weather & 2000,2005 & CMDC \\
\hline & & stations & 2010,2015 & (http://data.cma.cn/) \\
\hline \multirow[t]{3}{*}{ Topography } & Elevation & $30 \mathrm{~m}$ & - & $\begin{array}{c}\text { ASTER GDEM } \\
\text { (http://www.gscloud.cn/) }\end{array}$ \\
\hline & Slope & $30 \mathrm{~m}$ & - & $\begin{array}{l}\text { Extracted from GDEM } \\
\text { (http://www.gscloud.cn/) }\end{array}$ \\
\hline & Aspect & $30 \mathrm{~m}$ & - & $\begin{array}{l}\text { Extracted from GDEM } \\
\text { (http://www.gscloud.cn/) }\end{array}$ \\
\hline \multirow[t]{3}{*}{ Landcover } & Residential land & county level & $\begin{array}{l}2000,2005 \\
2010,2015\end{array}$ & Ministry of Land and Resources, P.R.C \\
\hline & Water body & county level & $\begin{array}{l}2000,2005 \\
2010,2015\end{array}$ & Ministry of Land and Resources, P.R.C \\
\hline & Unused land & county level & $\begin{array}{l}2000,2005 \\
2010,2015\end{array}$ & Ministry of Land and Resources, P.R.C \\
\hline \multirow[t]{7}{*}{$\begin{array}{l}\text { Social } \\
\text { economy }\end{array}$} & GDP per capita & county level & $\begin{array}{l}2000,2005 \\
2010,2015\end{array}$ & $\begin{array}{c}\text { China Statistical Yearbook (CSY)/ } \\
\text { Guangdong Statistical Yearbook (GSY) } \\
\text { (https://data.cnki.net/Yearbook/) }\end{array}$ \\
\hline & $\begin{array}{l}\text { Income of rural } \\
\text { residents }\end{array}$ & county level & $\begin{array}{l}2000,2005 \\
2010,2015\end{array}$ & $\begin{array}{c}\text { CSY/GSY } \\
\text { (https://data.cnki.net/Yearbook/) }\end{array}$ \\
\hline & Population & county level & $\begin{array}{l}2000,2005 \\
2010,2015\end{array}$ & $\begin{array}{c}\text { CSY/GSY } \\
\text { (https://data.cnki.net/Yearbook/) }\end{array}$ \\
\hline & $\begin{array}{l}\text { Gross industrial output } \\
\text { value }\end{array}$ & county level & $\begin{array}{l}2000,2005 \\
2010,2015\end{array}$ & $\begin{array}{c}\text { CSY/GSY } \\
\text { (https://data.cnki.net/Yearbook/) }\end{array}$ \\
\hline & Local fiscal revenue & county level & $\begin{array}{l}2000,2005 \\
2010,2015\end{array}$ & $\begin{array}{c}\text { CSY/GSY } \\
\text { (https://data.cnki.net/Yearbook/) }\end{array}$ \\
\hline & Fixed asset investment & county level & $\begin{array}{l}2000,2005 \\
2010,2015\end{array}$ & $\begin{array}{c}\text { CSY/GSY } \\
\text { (https://data.cnki.net/Yearbook/) }\end{array}$ \\
\hline & $\begin{array}{l}\text { Total retail sales of } \\
\text { consumer goods }\end{array}$ & county level & $\begin{array}{l}2000,2005 \\
2010,2015\end{array}$ & $\begin{array}{c}\text { CSY/GSY } \\
\text { (https://data.cnki.net/Yearbook/) }\end{array}$ \\
\hline
\end{tabular}

\section{Methodology}

\subsection{Selection of Driving Factors}

As one of the basic parameter estimation methods in the traditional linear regression model, the ordinary least squares model (OLS) assumes that the parameter estimates of the study area are constant. OLS is considered as a global modeling method, and its parameter estimates ignore the 
spatial distribution and relationship changes between independent variables and dependent variables. The OLS model can be defined as:

$$
y_{i}=\beta_{0}+\sum_{k=1}^{p} \beta_{k} x_{i k}+\varepsilon
$$

where $y_{i}$ represents dependent variable, $x_{i k}$ represents independent variable, $\beta_{0}$ represents intercept of the model, $\beta_{k}$ represents the parameter estimation of independent variable $x_{k}, p$ represents the number of impact factors, and $\varepsilon$ represents the error terms.

In the meantime, a stepwise regression (SR) model is a linear regression that automatically selects statistical models [29]. The basic principle of the stepwise regression is to introduce the explanatory variables step by step, i.e., introducing variables that have the most significant influence on specific dependent variables at each time step. Each variable entry is individually tested. When originally entered variables are no longer significant because of the introduction of a subsequent variable, the regression is culled and then considers introducing new variables until no variables can be culled. This process is repeated until new variables cannot be introduced and all independent variables in the regression equation are significant. Therefore, it is possible to use stepwise regression to select the explanatory variables that are significantly related to the dependent variable.

\subsection{Fractional Vegetation Cover Estimation}

The dimidiate pixel model is a vegetation estimation model, which assumes that the real surface of one pixel consists of vegetation-covered and non-vegetation-covered [30]. The spectral information observed by the sensor is linearly weighted by these two-component factors, and the weight of each factor is the ratio of its area in the pixel. The principle model principle is as follows:

$$
P=P_{v}+P_{s}
$$

where $P$ is the information observed by remote sensing sensors, $P_{v}$ is green vegetation information, and $P_{S}$ is the information of non-vegetation, which represents soil area.

FVC is the ratio of the vertical projection area of the vegetation canopy to the total soil area. Assuming that $P_{\text {veg }}$ is the pixel information of FVC in remote sensing image, and the pixel information of soil without vegetation is $P_{\text {soil }}$, the contribution of vegetation to the pixel can be expressed as:

$$
P_{v}=P_{v e g} \times f_{v c}
$$

The contribution of soil to the pixel is expressed as Equation (4):

$$
P_{s}=\left(1-f_{v c}\right) \times P_{\text {soil }}
$$

Therefore, the information observed based on remote sensing images is calculated as:

$$
P=P_{v e g} \times f_{v c}+\left(1-f_{v c}\right) \times P_{\text {soil }}
$$

In summary, the fractional vegetation cover is expressed as:

$$
f_{v c}=\left(P-P_{\text {soil }}\right) /\left(P_{\text {veg }}-P_{\text {soil }}\right)
$$

The model reflects the relationship between remote sensing information and FVC, and reduces the impact of atmosphere and soil as much as possible to retain only FVC information. Meanwhile, the Normalized Difference Vegetation Index (NDVI) is an important parameter that reflects crop growth and vegetation coverage information and is often used to estimate fractional vegetation cover in the dimidiate pixel model. The value of NDVI is substituted into Formula (6): 


$$
f_{v c}=\left(N D V I-N D V I_{s o i l}\right) /\left(N D V I_{v e g}-N D V I_{\text {soil }}\right)
$$

Therefore, according to Equation (7), the NDVI value of a pixel (NDVI) can be expressed as a combination of the information contributed by the vegetation $\left(N D V I_{v e g}\right)$ and soil $\left(N D V I_{\text {soil }}\right)$ areas.

\subsection{Semiparametric GWR Method}

The Geographically Weighted Regression (GWR) model is a local spatial modelling technique and an extension of the traditional linear regression model, which primarily considers spatial heterogeneity when analysing the spatial relationship among geographical objects [31]. The GWR model can be expressed as:

$$
y_{i}=\beta_{0}\left(u_{i}, v_{i}\right)+\sum_{k=1}^{p} \beta_{k}\left(u_{i}, v_{i}\right) x_{i k}+\varepsilon_{i}
$$

where $\left(u_{i}, v_{i}\right)$ represents the geographic location of the ith point, $y_{i}$ represents the fitting value of dependent variable at location $i, \beta_{k}\left(u_{i}, v_{i}\right)$ represents the local parameter estimate for the independent variable $k$ at location $i, \beta_{0}\left(u_{i}, v_{i}\right)$ and $\varepsilon_{i}$ represent the estimated intercept and error term for location $i$, respectively, and $\beta_{k}\left(u_{i}, v_{i}\right)$ is estimated by the weighted least square method and expressed in matrix form as follows:

$$
\hat{\beta}\left(u_{i}, v_{i}\right)=\left[X^{T} W\left(u_{i}, v_{i}\right) X\right]^{-1} X^{T} W\left(u_{i}, v_{i}\right) Y
$$

where $W\left(u_{i}, v_{i}\right)$ is a spatial weight matrix, and $X$ and $Y$ are the independent variable and dependent variable matrixes, respectively.

The simultaneous spatial heterogeneity and homogeneity of the impact factors of vegetation cover dynamics are difficult solve using only the local parameters included in the spatial regression model performed by the GWR [32,33]. This study used a mixed semi-parametric geographically weighted regression (SGWR) model—an extension of traditional GWR local space modelling — to study the relationship between fractional vegetation cover change and impact factors, and contains local and global coefficients to simultaneously analyse the spatial stationarity and non-stationarity of the impact factors. The SGWR model can be expressed as follow:

$$
y_{i}=\beta_{0}\left(u_{i}, v_{i}\right)+\sum_{l=1}^{j} \alpha_{l} x_{i l}+\sum_{k=j+1}^{p} \beta_{k}\left(u_{i}, v_{i}\right) x_{i k}+\varepsilon_{i}
$$

where $\alpha_{l}$ represents the global regression parameter estimation of independent variable $x_{i l}$. The kernel function is one of the key parameters in the SGWR model, which includes the Poisson function, Gaussian function, and logistic regression function methods. The Gaussian function is usually chosen as the kernel function of spatial weight:

$$
w_{i j}=\exp \left[-\left(\frac{d_{i j}}{b}\right)^{2}\right]
$$

where $d_{i j}$ is the distance between location point $j$ and $i ; b$ is the bandwidth, a non-negative attenuation parameter describing the functional relationship between weight and distance.

A geographic variability test (GVT) is used to determine local and global variables in the SGWR model based on the comparison of multiple GWR models. The Akaike information criterion (AIC) values of two GWR models were compared to evaluate the geographic variability of the kth independent variable. The standard deviation of the geographic variability test (DIFF of criterion) is introduced to test the geographic variability of the $k$ th variable. A positive value of DIFF of criterion indicates that the corresponding variable does not have geographic variability, whereas a negative value indicates that the variable has geographic variability in space. 
For comparison purposes, we fitted the ordinary least squares model (OLS) and the GWR regression using with the same dataset and variables. The three models were compared using the Akaike information criterion (AIC), residual sum of squares, and adjusted $R^{2}$ values [34,35]. The model with a lower AIC value means better fits the true value. The sum of the squares of the residuals is the sum of the squares of the differences between the actual value and the model simulation value; therefore, smaller sums denote higher fitting accuracy. The adjusted R-square value better represents the fitting degree of the model to the data for multiple regression analysis models.

\section{Results}

\subsection{Regional Variations of Vegetation Coverage}

From 2000-2015, annual average fractional vegetation cover in Guangdong Province remained unchanged, and FVC was generally high; Figure 2 shows the regional spatiotemporal change differences by county. The FVC of 13 prefecture-level cities in the study area showed a steady growth trend, whereas urbanisation development caused a slight decrease in 8 prefecture-level cities.

Heyuan, Shaoguan, and Yunfu have the highest vegetation coverage because of the extremely suitable temperature and moisture conditions of the mountainous area of northwest Guangdong. Additionally, the underdeveloped economy of these areas results in low deforestation. In contrast, Foshan City and Zhuhai City have the lowest vegetation coverage, whereas other cities have vegetation coverage of more than 0.5. Since the 21st century, the rapid economic development of Foshan has led to the destruction of vegetation in urban construction areas. However, the increasing vegetation coverage in Foshan shows the great importance attached by the government to urban greening and vegetation protection; the greening effect also remediates ecological and environment damage caused by economic development. The low FVC in Zhuhai reflects the large number of islands in the prefecture and the persistent negative environmental and ecological effects of economic development in the Pearl River Delta.

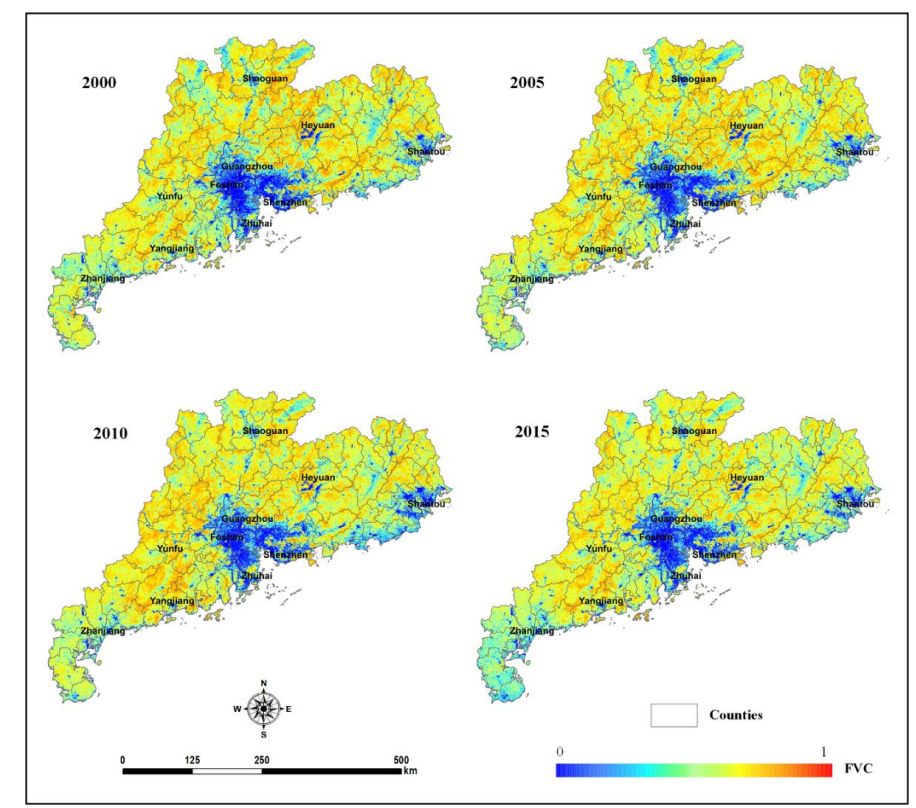

Figure 2. Fractional Vegetation Cover (FVC) from 2000 to 2015 in the study area.

\subsection{Statistical Analysis and Model Assessment}

\subsubsection{FVC and Major Driving Factors: OLS, GWR, and SGWR}

FVC driving factors included climate, terrain, land cover, and socio-economic factors. According to the stepwise regression method and correlation test, the major driving factors affecting vegetation 
coverage were selected from the independent variables by the stepwise regression method. In our study, elevation, sunshine duration, rainfall, urban land, population, GDP per capita, and gross industrial output value were used as the primary driving factors in the OLS, GWR, and SGWR models to reveal the complex relationship with the FVC.

OLS, GWR, and SGWR models were established to analyse and compare the relationships between FVC and major driving factors. Table 2 represents the coefficient estimates for the global regression models. According to the $\mathrm{R}^{2}$, the performance of OLS model in 2015 is better than that of other OLS models: the independent variable effectively explains approximately $58 \%$ of the fractional vegetation cover variable. Global variable estimates vary by period. The estimated values of elevation, sunshine duration, and rainfall in the OLS model are positive in the four periods from 2000-2015, implying the positive correlation of those factors with FVC. Thus, a county with a relatively high average elevation has a greater degree of FVC. The positive value of the sunshine duration coefficient decreases from 2000-2015, possibly owing to increased air pollution caused by development in the Pearl River Delta, which leads to fluctuating, decreased, and weakened sunshine in Guangdong.

Table 2. Global estimates from ordinary least squares (OLS) model.

\begin{tabular}{|c|c|c|c|c|}
\hline Variables & 2000 & 2005 & 2010 & 2015 \\
\hline Intercept & $0.470 *$ & $0.495 *$ & 0.404 * & $0.389 *$ \\
\hline Elevation & 0.038 & 0.049 & $0.046^{*}$ & 0.050 * \\
\hline Sunshine duration & $0.117 *$ & 0.114 * & $0.102 *$ & $0.099 *$ \\
\hline Rainfall & $0.033 *$ & $0.027^{*}$ & $0.031 *$ & 0.030 * \\
\hline Urban land & -0.104 * & $-0.112 *$ & $-0.128 *$ & -0.138 * \\
\hline Population & -0.050 * & -0.058 * & $-0.069 *$ & $-0.067^{*}$ \\
\hline GDP per capita & $-0.056^{*}$ & -0.059 & -0.070 & -0.074 * \\
\hline Gross industrial output value & -0.036 & -0.038 & $-0.045 *$ & -0.052 * \\
\hline $\mathbf{R}^{2}$ & 0.462 & 0.481 & 0.537 & 0.579 \\
\hline
\end{tabular}

Table 3 displays statistics of the local GWR model estimates. A set of local estimates varying with the geographical locations of the counties were derived from the GWR for each variable. The spatial heterogeneity of the estimates of different variables shows that the relationship between FVC and major driving factors has a spatial, non-stationary relationship with changes in location. For example, the global and local estimates for rainfall in 2010 were 0.031 and $-0.003-0.047$, respectively. The median value of local estimates in the GWR model is different from that of the OLS model. Global rainfall estimates from 2000-2015 range from 0.027-0.033, whereas median local estimates range from 0.022-0.029. Differences in the overall impact of rainfall on FVC in different periods may largely depend on the irregular fluctuation of annual accumulated rainfall and the uneven time distribution of rainfall in the study area.

Local and global model variables must be distinguished to obtain the fitting results of the SGWR model. A geographical variability test performed to determine the local and global variables shows that elevation, sunshine duration, rainfall, urban land, and population have a negative DIFF, and are assumed to be local variables owing to their significant spatial heterogeneity (Table 4). In contrast, GDP per capita and gross industrial output values are assumed to be global variables with a positive DIFF in the GVT. Table 5 shows the statistical results of global and local estimates of the SGWR model for fractional vegetation cover, which considers spatial stability and non-stationarity. The local estimates for urban land in each period are negative, indicating that the local influence of urban land expansion on FVC in the study area is negatively correlated, perhaps owing to accelerated urbanisation in the past two decades and increasing demand for land resources in urban construction. Additionally, the GVT determined that the population factor had a geographical variability in the SGWR, with local estimates ranging from -0.102 to -0.003 and -0.120 to -0.011 in 2000 and 2015 , respectively. 
Table 3. Local estimates from Geographically Weighted Regression (GWR) model.

\begin{tabular}{|c|c|c|c|c|c|c|c|c|c|c|c|c|}
\hline \multirow{2}{*}{ Variable } & \multicolumn{4}{|c|}{2000} & \multicolumn{3}{|c|}{2005} & \multicolumn{3}{|c|}{2010} & \multicolumn{2}{|c|}{2015} \\
\hline & Min & Max & Median & Min & Max & Median & Min & Max & Median & Min & Max & Median \\
\hline Intercept & 0.227 & 0.595 & 0.419 & 0.284 & 0.670 & 0.452 & 0.195 & 0.542 & 0.388 & 0.168 & 0.496 & 0.370 \\
\hline Elevation & -0.005 & 0.049 & 0.034 & 0.003 & 0.063 & 0.044 & -0.002 & 0.055 & 0.038 & -0.001 & 0.057 & 0.046 \\
\hline Sunshine duration & 0.036 & 0.152 & 0.115 & 0.023 & 0.136 & 0.109 & 0.014 & 0.138 & 0.097 & 0.008 & 0.127 & 0.095 \\
\hline Rainfall & -0.003 & 0.049 & 0.028 & 0.000 & 0.039 & 0.022 & -0.003 & 0.047 & 0.029 & -0.001 & 0.042 & 0.024 \\
\hline Urban land & -0.186 & -0.014 & -0.110 & -0.213 & -0.024 & -0.119 & -0.221 & -0.027 & -0.130 & -0.230 & -0.033 & -0.142 \\
\hline Population & -0.098 & -0.006 & -0.051 & -0.105 & -0.021 & -0.062 & -0.109 & -0.013 & -0.072 & -0.114 & -0.018 & -0.066 \\
\hline GDP per capita & -0.096 & 0.004 & -0.062 & -0.103 & -0.005 & -0.067 & -0.114 & -0.012 & -0.075 & -0.173 & -0.462 & -0.080 \\
\hline Gross industrial output value & -0.071 & -0.010 & -0.039 & -0.084 & -0.007 & -0.044 & -0.089 & -0.015 & -0.048 & -0.086 & -0.017 & -0.053 \\
\hline
\end{tabular}

Table 4. Geographical variability of the variables

\begin{tabular}{|c|c|c|c|c|c|c|c|c|}
\hline \multirow[b]{2}{*}{ Variable } & \multicolumn{2}{|c|}{2000} & \multicolumn{2}{|c|}{2005} & \multicolumn{2}{|c|}{2010} & \multicolumn{2}{|c|}{2015} \\
\hline & $\begin{array}{c}\text { DIFF of } \\
\text { Criterion }\end{array}$ & $\begin{array}{c}\text { Geographical } \\
\text { Variability }\end{array}$ & $\begin{array}{l}\text { DIFF of } \\
\text { Criterion }\end{array}$ & $\begin{array}{c}\text { Geographical } \\
\text { Variability }\end{array}$ & $\begin{array}{l}\text { DIFF of } \\
\text { Criterion }\end{array}$ & $\begin{array}{c}\text { Geographical } \\
\text { Variability }\end{array}$ & $\begin{array}{l}\text { DIFF of } \\
\text { Criterion }\end{array}$ & $\begin{array}{c}\text { Geographical } \\
\text { Variability }\end{array}$ \\
\hline Intercept & -1.275 & $\sqrt{ }$ & -1.432 & $\sqrt{ }$ & -1.598 & $\sqrt{ }$ & -1.341 & $\sqrt{ }$ \\
\hline Elevation & -0.122 & $\sqrt{ }$ & -0.180 & $\sqrt{ }$ & -0.127 & $\sqrt{ }$ & -0.141 & $\sqrt{ }$ \\
\hline Sunshine duration & -0.489 & $\sqrt{ }$ & -0.624 & $\sqrt{ }$ & 0.331 & & -0.295 & $\sqrt{ }$ \\
\hline Rainfall & 0.096 & & -0.151 & $\sqrt{ }$ & -0.076 & $\sqrt{ }$ & -0.172 & $\sqrt{ }$ \\
\hline Urban land & -0.393 & $\sqrt{ }$ & -0.306 & $\sqrt{ }$ & -0.438 & $\sqrt{ }$ & -0.273 & $\sqrt{ }$ \\
\hline Populatoin & -0.258 & $\sqrt{ }$ & -0.204 & $\sqrt{ }$ & -0.351 & $\sqrt{ }$ & -0.105 & $\sqrt{ }$ \\
\hline GDP per capita & 0.096 & & 0.051 & & 0.062 & & 0.167 & \\
\hline Gross industrial output value & 0.107 & & 0.128 & & 0.094 & & 0.024 & \\
\hline
\end{tabular}


Table 5. Local and global estimates from Semi-parametric Geographically Weighted Regression (SGWR) model.

\begin{tabular}{|c|c|c|c|c|c|c|c|c|c|c|c|c|}
\hline \multirow{3}{*}{ Variable } & \multicolumn{12}{|c|}{ Local Coefficients } \\
\hline & \multicolumn{3}{|c|}{2000} & \multicolumn{3}{|c|}{2005} & \multicolumn{3}{|c|}{2010} & \multicolumn{3}{|c|}{2015} \\
\hline & Min & $\operatorname{Max}$ & Median & Min & $\operatorname{Max}$ & Median & Min & $\operatorname{Max}$ & Median & Min & $\operatorname{Max}$ & Median \\
\hline Intercept & 0.204 & 0.618 & 0.449 & 0.257 & 0.700 & 0.471 & 0.172 & 0.573 & 0.405 & 0.157 & 0.536 & 0.391 \\
\hline Elevation & -0.009 & 0.056 & 0.036 & -0.001 & 0.066 & 0.045 & -0.006 & 0.062 & 0.039 & -0.003 & 0.065 & 0.048 \\
\hline Sunshine duration & 0.028 & 0.157 & 0.118 & 0.017 & 0.142 & 0.105 & 0.012 & 0.145 & 0.101 & 0.006 & 0.130 & 0.092 \\
\hline Rainfall & -0.006 & 0.051 & 0.030 & -0.002 & 0.043 & 0.025 & -0.007 & 0.053 & 0.034 & -0.003 & 0.046 & 0.029 \\
\hline Urban land & -0.193 & -0.012 & -0.107 & -0.217 & -0.018 & -0.116 & -0.226 & -0.025 & -0.132 & -0.237 & -0.027 & -0.145 \\
\hline Population & -0.102 & -0.003 & -0.058 & -0.109 & -0.014 & -0.063 & -0.115 & -0.008 & -0.067 & -0.120 & -0.011 & -0.069 \\
\hline \multicolumn{13}{|c|}{ Global Coefficients } \\
\hline Variable & Estimate & \multicolumn{2}{|c|}{ Standard Error } & Estimate & \multicolumn{2}{|c|}{ Standard Error } & Estimate & \multicolumn{2}{|c|}{ Standard Error } & Estimate & \multicolumn{2}{|c|}{ Standard Error } \\
\hline GDP per capita & -0.057 & \multicolumn{2}{|c|}{0.248} & -0.064 & \multicolumn{2}{|c|}{0.215} & -0.070 & \multicolumn{2}{|c|}{0.169} & -0.073 & \multicolumn{2}{|c|}{0.157} \\
\hline Gross industrial output value & -0.038 & \multicolumn{2}{|c|}{0.256} & -0.041 & \multicolumn{2}{|c|}{0.277} & -0.045 & \multicolumn{2}{|c|}{0.140} & -0.046 & \multicolumn{2}{|c|}{0.163} \\
\hline
\end{tabular}




\subsubsection{Comparison of Model Accuracy}

The primary difference between the SGWR, OLS, and GWR models is that OLS does not capture the spatial autocorrelation and spatial dependence in the error term. However, the GWR model does not consider the limitations of using local parameters to analyse the driving factors of vegetation cover. The SGWR model is an improvement of the OLS and GWR models, does not ignore the spatial heterogeneity of the variables, and improves the accuracy of the spatial analysis by combining local and global estimates.

The AIC value of the SGWR model is lower than that of the OLS and GWR models during the study period, and the model fitting accuracy is variably improved. Table 6 shows that the AIC value of the SGWR model was 759.462 in 2015, which was 112.634 and 54.053 lower than that of the OLS and GWR models, respectively. The SGWR model improved the OLS and GWR models better in 2015 than in other years. The results of the SGWR showed that the adjusted $\mathrm{R}^{2}$ values of the model for the entire period are $0.706,0.803,0.820$, and 0.829 , indicating that the SGWR model explains more than $78 \%$ of the fractional vegetation cover dynamics and that the selected driving factors have a significant impact on FVC in Guangdong.

Table 6. Comparison of Akaike information criterion (AIC), residual sum of squares, and adjusted $\mathrm{R}^{2}$ values for the OLS, GWR, and SGWR models.

\begin{tabular}{|c|c|c|c|c|}
\hline Models & 2000 & 2005 & 2010 & 2015 \\
\hline OLS AIC & 930.521 & 900.004 & 878.957 & 862.096 \\
\hline GWR AIC & 872.605 & 860.799 & 821.530 & 803.515 \\
\hline SGWR AIC & 844.831 & 817.562 & 770.801 & 749.462 \\
\hline OLS RSS & 391.056 & 411.024 & 387.734 & 369.250 \\
\hline GWR RSS & 316.632 & 269.814 & 248.466 & 236.924 \\
\hline SGWR RSS & 301.748 & 241.942 & 206.329 & 181.205 \\
\hline OLS Adjusted $\mathrm{R}^{2}$ & 0.527 & 0.549 & 0.581 & 0.621 \\
\hline GWR Adjusted $R^{2}$ & 0.678 & 0.736 & 0.757 & 0.765 \\
\hline SGWR Adjusted $\mathrm{R}^{2}$ & 0.781 & 0.803 & 0.820 & 0.829 \\
\hline
\end{tabular}

\subsection{Spatially Varying Relationships between FVC and Driving Factors Explored by SGWR}

\subsubsection{The Results of Local Parameters on a County Level}

The parameter estimates of local and global model variable are mapped for each of the four periods. However, only those local parameter estimates that were significant are depicted. In this case, significance is defined using the adjusted critical $t$ value equated with an original significance level of 0.05 , which addresses the issue of multiple hypothesis testing and multiple testing issue in GWR [36,37].

Figures 3-6 show the local estimates produced by SGWR for the major driving factors of fractional vegetation cover, including sunshine duration, rainfall, urban land, and population. According to the results of the SGWR model, local sunshine duration and rainfall estimates for the four periods featured significant geospatial heterogeneity. Although all the local sunshine duration estimates indicate a positive association between fractional vegetation cover and sunshine intensity, the strength of the relationship varies across space. For example, the sunshine duration in 2000 greatly impacted the vegetation coverage of Qingyuan city. However, the estimated value of the sunshine duration decreased significantly after 2010, indicating the recent weakening influence of sunshine intensity on FVC in most counties in Qingyuan City. 

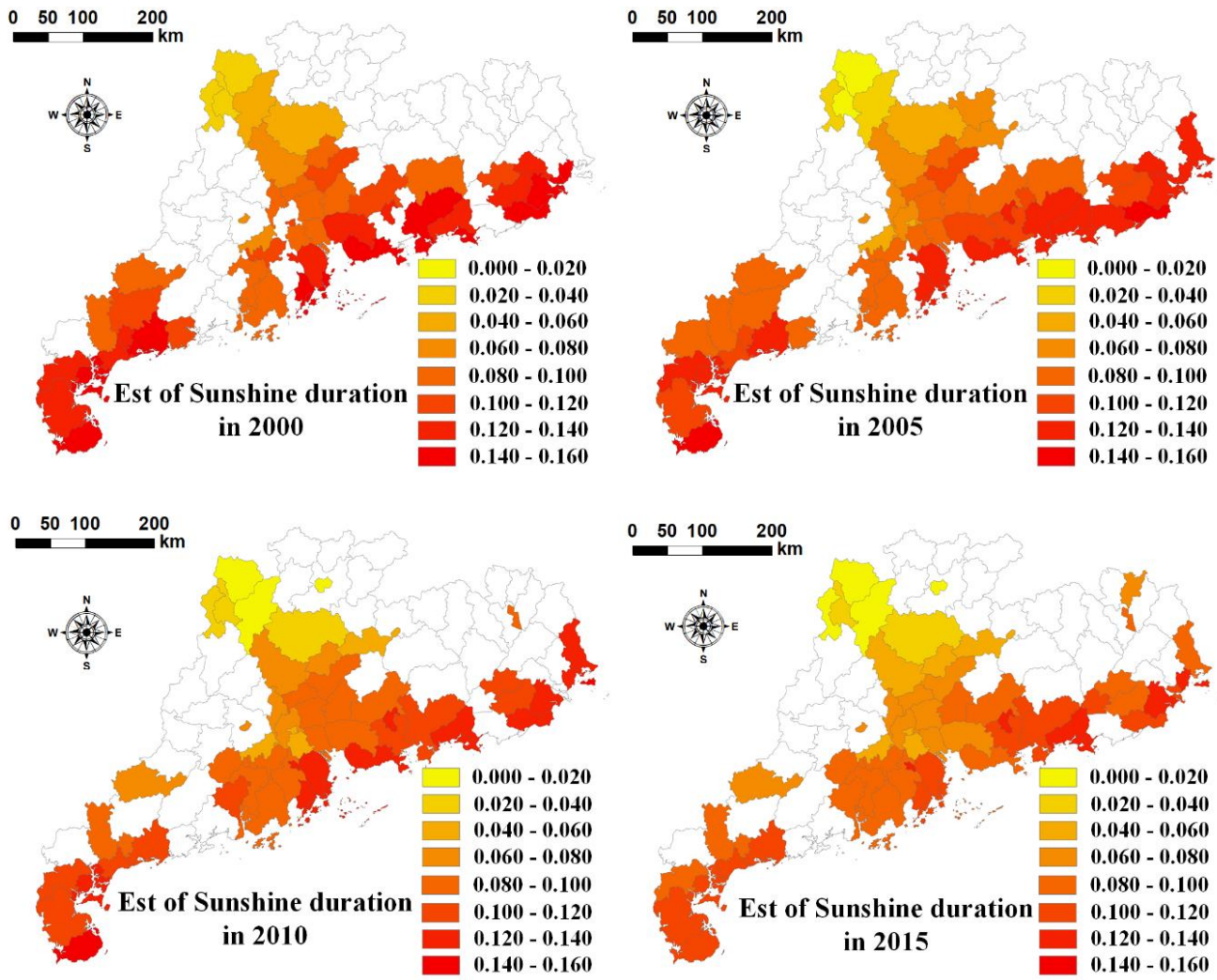

Figure 3. Local estimates for Sunshine duration factor of Fractional Vegetation Cover (FVC) calculated by the SGWR model.
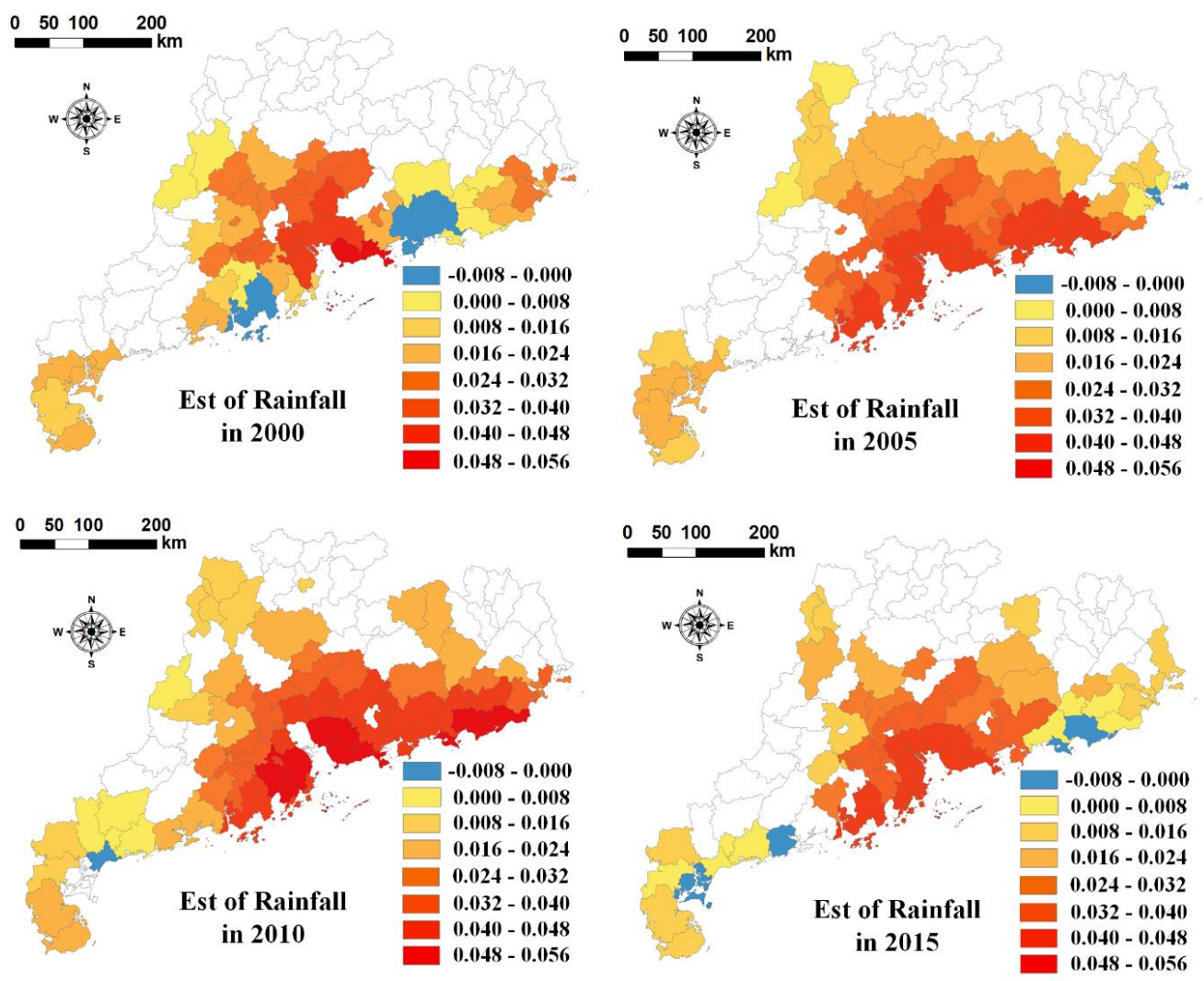

Figure 4. Local estimates for Rainfall factor of Fractional Vegetation Cover (FVC) calculated by the SGWR model. 

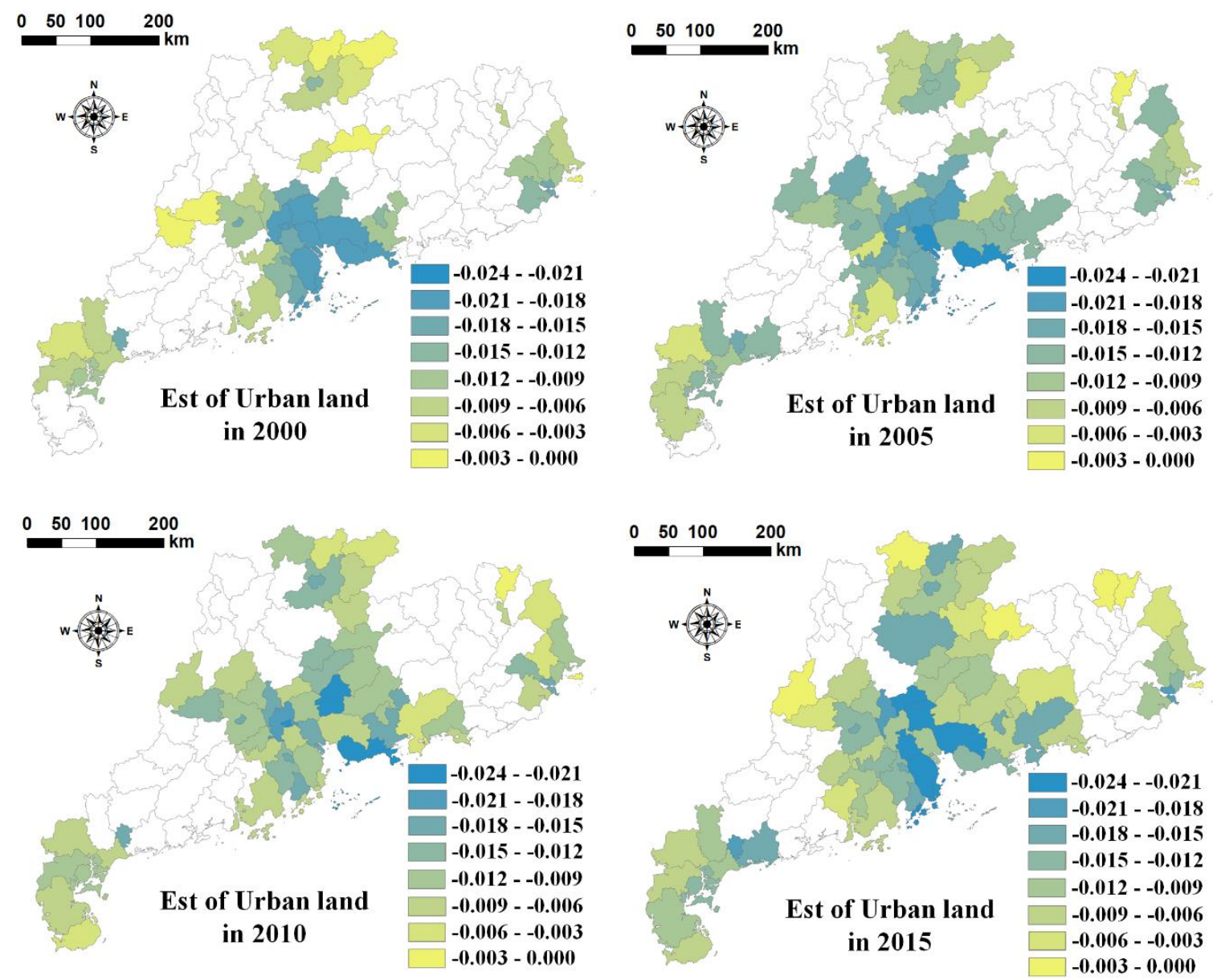

Figure 5. Local estimates for Urban land factor of Fractional Vegetation Cover (FVC) calculated by the SGWR model.

In contrast, the alternating positive and negative effects of the rainfall coefficient and the large proportion of positive effects reveal that rainfall is the principal factor affecting FVC (Figure 4); coastal rainfall promotes plant growth, whereas rainfall at typhoon landfall locations negatively impacts vegetation cover. With regard to the impact of urban land, Figure 5 indicates that the local influence of most urban land on FVC in Guangdong Province is negatively correlated, primarily because of accelerated urbanisation from 2000-2015 and the consequential increase in the demand for cultivated and forested land.

Increasing population decreases vegetation coverage area because of the negative correlation between population and FVC. Population growth in the study area has led to rapid economic and real estate development, urban expansion, and demand for residential land. In contrast, the inland mountainous areas of northern Guangdong (such as Shaoguan City and Heyuan City) have low population density. The outflow of population from this region leads to a marked difference to the Pearl River Delta and explains the low sensitivity of this region to the population factor. 

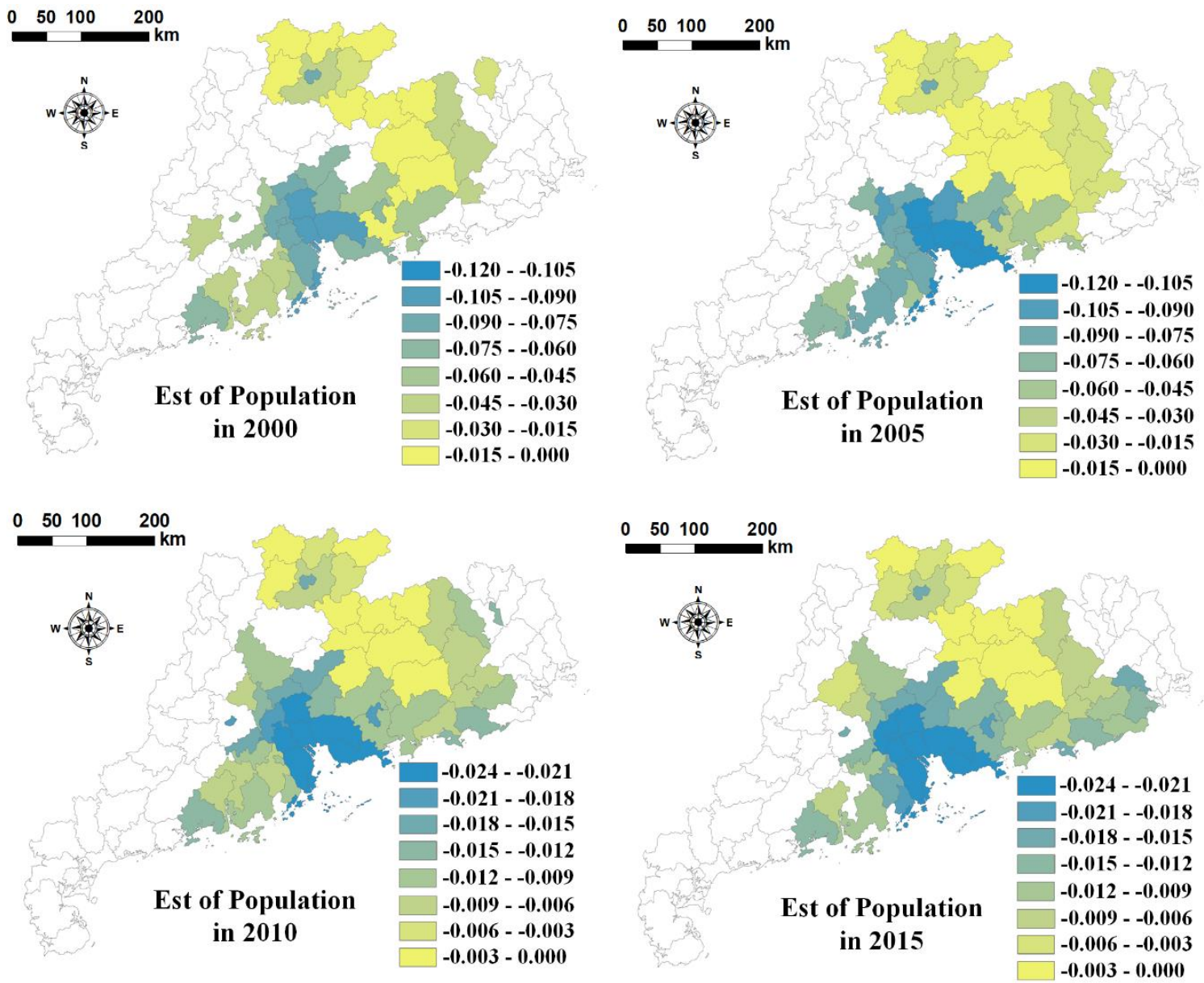

Figure 6. Local estimates for Population factor of Fractional Vegetation Cover (FVC) calculated by the SGWR model.

\subsubsection{The Performance of SGWR Modelling in Comparison with GWR}

The adjusted $R^{2}$ of the GWR and SGWR models are visually displayed and highlight the spatial heterogeneity of the simulation effect. The modelling system performance can be demonstrated by the adjusted $R^{2}$ values, which usually describe the fitting degree of the regression model to observation data and remove disturbances from the explanatory variable on $R^{2}$. The adjusted $R^{2}$ of the SGWR model is the closest to 1 ; therefore, the SGWR model better explains regional vegetation coverage variations. The adjusted $R^{2}$ of the GWR model generally ranges from $0.4-0.8$, whereas the average adjusted $R^{2}$ of the SGWR model is greater than 0.8 (Figure 7). The lower adjusted $R^{2}$ values in Heyuan and Yunfu indicate an insignificant association between vegetation coverage and model driving factors, whereas the relatively higher adjusted $R^{2}$ values in Guangzhou, Huizhou, and Dongguan indicate a stronger positive correlation. The high adjusted $R^{2}$ value of the SGWR verifies that the fitting accuracy is significantly better than that of the GWR model.

By analysing the research times of the models, we found the highest adjusted $R^{2}$ in 2015 . The SGWR improvement from 2000-2015 ranged from $0.21-0.45$ and 0.26-0.67 in northern Guangdong and the Pearl River Delta, respectively, and more than $50 \%$ of counties had adjusted $\mathrm{R}^{2}$ values higher than 0.8 in 2015 (35 more than in 2000). 

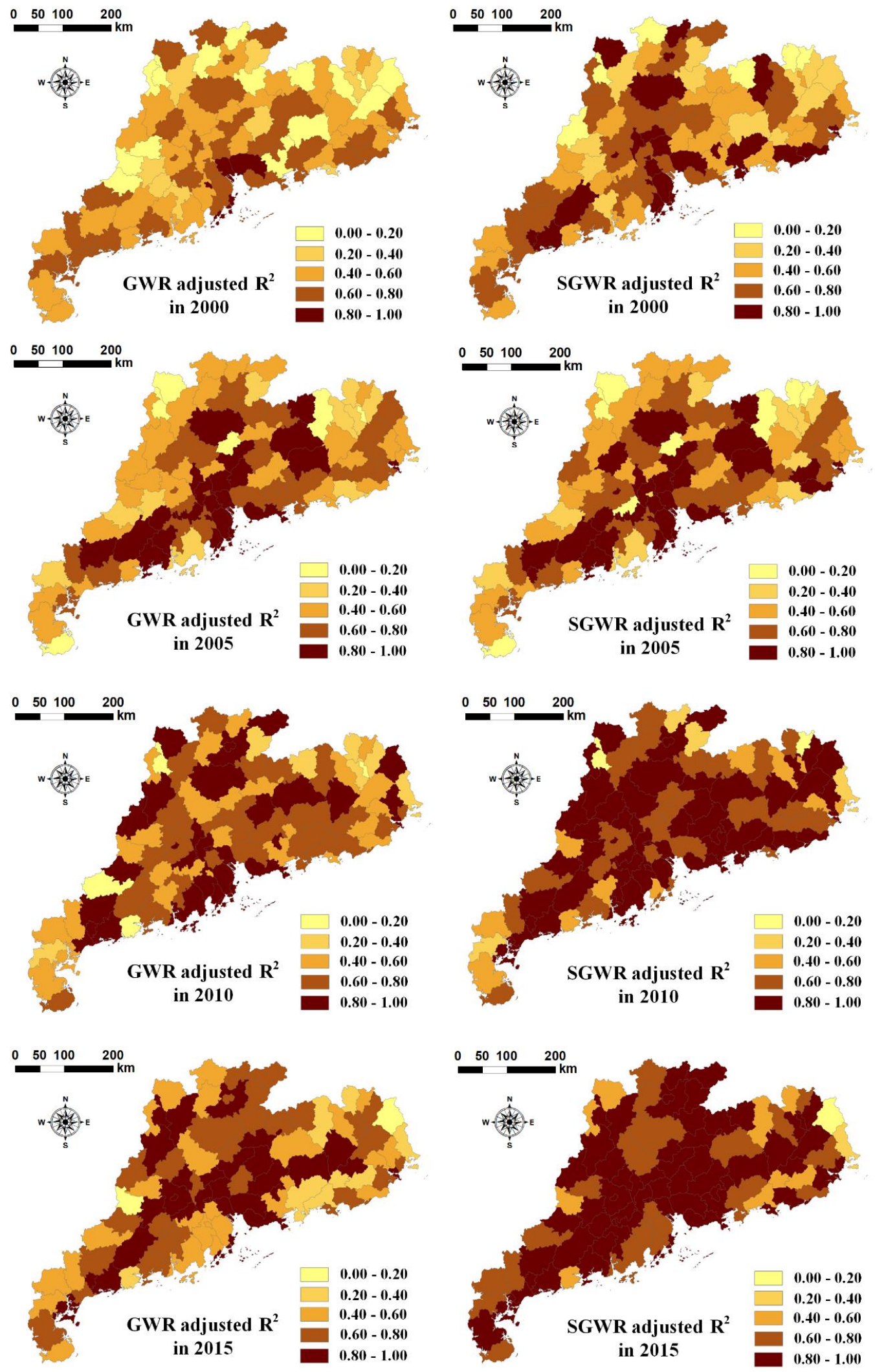

Figure 7. Local adjusted $R^{2}$ for fractional vegetation cover calculated by the GWR and SGWR models.

The SGWR fixes some parameters across space and allows others to change spatially to simultaneously represent stationary and non-stationary spatial relationships and processes between FVC and the driving factors. Another advantage of the SGWR model is its ability to explore the spatial 
heterogeneity and homogeneity of the relationship between fractional vegetation cover and explanatory variables with the geographic variability test. Nonetheless, the SGWR model should be used with caution. Global or local variables in the geographic variability test affect the final analysis results and should be carefully selected. Additionally, the spatial relationship in the model is established by the spatial weight matrix, and the spatial weight matrix bandwidth setting is uncertain.

\section{Discussion}

The relationship between vegetation cover variations and driving factors in Guangdong is a response to rapid urbanisation and government policies. [38]. Guangdong regulated the management and protection of forest land in 1998 and aimed to reforest barren mountains and promote the development of national forestry reform [39]. Although urbanisation in the Pearl River Delta encroaches on regional vegetation, total vegetation cover in the study area has remained constant with the implementation of policies and regulations. We hope to strengthen the pace of ecological and environmental construction and to expand the coverage and distribution of vegetation in Guangdong. A coastal ecological and environmental protection zone needs to be established, and efforts should be made to improve the forest quality in western and eastern Guangdong. The compensation mechanism for ecological benefits should be further improved, and the provincial relationship between ecological and economic construction should be reasonably coordinated.

Several areas merit further research. First, more factors can be introduced into SGWR analyses to consider other drivers that might contribute to FVC dynamics, such as population quality and government financial subsidy data (if available). Second, in addition to the analysis of vegetation cover change, spatial regression analysis performed for net primary productivity (NPP) could involve different driving forces. Finally, with additional data collection, the temporal dimension can be integrated into the regression analysis to account for the temporal associations of FVC.

The focus of the national development strategy in China has transitioned from economic growth to ecological progress since the 18th National Congress of the Communist Party of China (CPC) in 2012 because of the environmental and ecological issues caused by urbanisation; the ecological civilisation was again promoted at the 19th National Congress of the CPC in 2017 [40]. Sustainable utilisation and management of vegetation resources is the key to solving the contradiction between limited natural resources and economic development needs and is of great significance to long-term green and sustainable development. Regional FVC variations and potential driving factors must be further investigated because of the spatial heterogeneity of vegetation coverage distribution to make effective local ecological management and protection decisions.

\section{Conclusions}

In this research, the Semi-parametric Geographically Weighted Regression (SGWR) model of fractional vegetation cover was first constructed to represent stationary and non-stationary spatial relationships between FVC and driving factors on a county level. Most importantly, climate, terrain, land cover, and socio-economic factors were introduced into the models to determine which variables had a decisive impact on vegetation coverage in Guangdong from 2000-2015. These are the primary contributions of the research compared with previous studies.

The results show that selected driving factors (including elevation, sunshine duration, rainfall, urban land, and population) were assumed to be local variables due to their spatial heterogeneity, whereas GDP per capita and gross industrial output values were assumed to be global variables. The local coefficient estimates for urban land and population in each period had significantly negative associations with FVC in the study area. Rainfall and elevation had positive and negative alternating relationships, respectively, and the local estimates of sunshine duration indicate a positive association. Vegetation coverage in the Pearl River Delta declined slightly, and the total vegetation area of Guangdong remained unchanged, reflecting the spatial heterogeneity of vegetation coverage in the Province during the study period. Additionally, the SGWR model of fractional vegetation cover has 
higher fitting accuracy than the GWR model and represents more than $78 \%$ of the fractional vegetation cover dynamics in Guangdong from 2000-2015.

Author Contributions: Conceptualization, Y.J. and P.C.; Data curation, Y.J. and H.Z.; Funding acquisition, P.C.; Investigation, H.Z. and Y.Y.; Methodology, Y.J.; Resources, Y.J. and P.C.; Supervision, Y.J. and P.C.; Writing—original draft, Y.J.; Writing-review \& editing, Y.Y. All authors have read and agreed to the published version of the manuscript.

Funding: This research was funded by The Science and Technology Program of Guangzhou, grant number 201605030009,201803020036, Project supported by Guangdong Engineering and Research Center for Unmanned Aerial Vehicle Remote Sensing of Agricultural Water and Soil Information.

Acknowledgments: We would like to thank the College of Water Conservancy and Civil Engineering of South China Agricultural University for providing study materials and laboratory.

Conflicts of Interest: The authors declare no conflict of interest. The funders had no role in the design of the study; in the collection, analyses or interpretation of data; in the writing of the manuscript, or in the decision to publish the results.

\section{References}

1. Song, X.-P.; Hansen, M.C.; Stehman, S.V.; Potapov, P.V.; Tyukavina, A.; Vermote, E.F.; Townshend, J.R. Global land change from 1982 to 2016. Nature 2018, 560, 639-643. [CrossRef] [PubMed]

2. Seddon, A.W.R.; Macias-Fauria, M.; Long, P.R.; Benz, D.; Willis, K.J. Sensitivity of global terrestrial ecosystems to climate variability. Nature 2016, 531, 229. [CrossRef] [PubMed]

3. Peng, S.; Piao, S.; Ciais, P.; Myneni, R.B.; Chen, A.; Chevallier, F.; Dolman, A.J.; Janssens, I.A.; Penuelas, J.; Zhang, G. Asymmetric effects of daytime and night-time warming on Northern Hemisphere vegetation. Nature 2013, 501, 88-92. [CrossRef] [PubMed]

4. Zhu, Z.; Piao, S.; Myneni, R.B.; Huang, M.; Zeng, Z.; Canadell, J.G.; Ciais, P.; Sitch, S.; Friedlingstein, P.; Arneth, A. Greening of the Earth and its drivers. Nat. Clim. Chang. 2016, 6, 791. [CrossRef]

5. Gitelson, A.A. Remote estimation of crop fractional vegetation cover: The use of noise equivalent as an indicator of performance of vegetation indices. Int. J. Remote Sens. 2013, 34, 6054-6066. [CrossRef]

6. $\mathrm{Mu}, \mathrm{X} . ;$ Song, W.; Gao, Z.; McVicar, T.R.; Donohue, R.J.; Yan, G. Fractional vegetation cover estimation by using multi-angle vegetation index. Remote Sens. Environ. 2018, 216, 44-56. [CrossRef]

7. Gao, L.; Wang, X.; Johnson, B.A.; Tian, Q.; Wang, Y.; Verrelst, J.; Mu, X.; Gu, X. Remote sensing algorithms for estimation of fractional vegetation cover using pure vegetation index values: A review. ISPRS J. Photogramm. Remote Sens. 2020, 159, 364-377. [CrossRef]

8. Sun, W.; Song, X.; Mu, X.; Gao, P.; Wang, F.; Zhao, G. Spatiotemporal vegetation cover variations associated with climate change and ecological restoration in the Loess Plateau. Agric. For. Meteorol. 2015, 209, 87-99. [CrossRef]

9. Pearson, R.G.; Phillips, S.J.; Loranty, M.M.; Beck, P.S.A.; Damoulas, T.; Knight, S.J.; Goetz, S.J. Shifts in Arctic vegetation and associated feedbacks under climate change. Nat. Clim. Chang. 2013, 3, 673-677. [CrossRef]

10. Trondman, A.; Gaillard, M.; Mazier, F.; Sugita, S.; Fyfe, R.; Nielsen, A.B.; Twiddle, C.; Barratt, P.; Birks, H.J.B.; $B j u n e, A . E$. Pollen-based quantitative reconstructions of Holocene regional vegetation cover (plant-functional types and land-cover types) in Europe suitable for climate modelling. Glob. Chang. Biol. 2015, 21, 676-697. [CrossRef]

11. Kalisa, W.; Igbawua, T.; Henchiri, M.; Ali, S.; Zhang, S.; Bai, Y.; Zhang, J. Assessment of climate impact on vegetation dynamics over East Africa from 1982 to 2015. Sci. Rep. 2019, 9, 16865. [CrossRef] [PubMed]

12. Suepa, T.; Qi, J.; Lawawirojwong, S.; Messina, J.P. Understanding spatio-temporal variation of vegetation phenology and rainfall seasonality in the monsoon Southeast Asia. Environ. Res. 2016, 147, 621-629. [CrossRef] [PubMed]

13. Wang, J.; Wang, H.; Cao, Y.; Bai, Z.; Qin, Q. Effects of soil and topographic factors on vegetation restoration in opencast coal mine dumps located in a loess area. Sci. Rep. 2016, 6, 22058. [CrossRef] [PubMed]

14. Jin, Y.; Liu, X.; Chen, Y.; Liang, X. Land-cover mapping using Random Forest classification and incorporating NDVI time-series and texture: A case study of central Shandong. Int. J. Remote Sens. 2018, 39, 8703-8723. [CrossRef] 
15. Stow, D.A.; Hope, A.; McGuire, D.; Verbyla, D.; Gamon, J.; Huemmrich, F.; Houston, S.; Racine, C.; Sturm, M.; Tape, K. Remote sensing of vegetation and land-cover change in Arctic Tundra Ecosystems. Remote Sens. Environ. 2004, 89, 281-308. [CrossRef]

16. Jin, Y.; Liu, X.; Yao, J.; Zhang, X.; Zhang, H. Mapping the annual dynamics of cultivated land in typical area of the Middle-lower Yangtze plain using long time-series of Landsat images based on Google Earth Engine. Int. J. Remote Sens. 2020, 41, 1625-1644. [CrossRef]

17. Li, G.; Sun, S.; Han, J.; Yan, J.; Liu, W.; Wei, Y.; Lu, N.; Sun, Y. Impacts of Chinese Grain for Green program and climate change on vegetation in the Loess Plateau during 1982-2015. Sci. Total Environ. 2019, 660, 177-187. [CrossRef]

18. Chen, Y.; Wang, K.; Lin, Y.; Shi, W.; Song, Y.; He, X. Balancing green and grain trade. Nat. Geosci. 2015, 8, 739-741. [CrossRef]

19. Jiang, M.; Tian, S.; Zheng, Z.; Zhan, Q.; He, Y. Human activity influences on vegetation cover changes in Beijing, China, from 2000 to 2015. Remote Sens. 2017, 9, 271. [CrossRef]

20. Shen, Q.; Gao, G.; Han, F.; Xiao, F.; Ma, Y.; Wang, S.; Fu, B. Quantifying the effects of human activities and climate variability on vegetation cover change in a hyper-arid endorheic basin. Land Degrad. Dev. 2018, 29, 3294-3304. [CrossRef]

21. Ding, C. Land policy reform in China: Assessment and prospects. Land Use Policy 2003, 20, 109-120. [CrossRef]

22. Zhang, W.; Wang, W.; Li, X.; Ye, F. Economic development and farmland protection: An assessment of rewarded land conversion quotas trading in Zhejiang, China. Land Use Policy 2014, 38, 467-476. [CrossRef]

23. Feng, Z.; Yang, Y.; Zhang, Y.; Zhang, P.; Li, Y. Grain-for-green policy and its impacts on grain supply in West China. Land Use Policy 2005, 22, 301-312. [CrossRef]

24. Song, X.; Peng, C.; Zhou, G.; Jiang, H.; Wang, W. Chinese Grain for Green Program led to highly increased soil organic carbon levels: A meta-analysis. Sci. Rep. 2015, 4, 4460. [CrossRef] [PubMed]

25. Cao, S.; Shang, D.; Yue, H.; Ma, H. A win-win strategy for ecological restoration and biodiversity conservation in Southern China. Environ. Res. Lett. 2017, 12, 044004. [CrossRef]

26. Pei, F.; Li, X.; Liu, X.; Lao, C.; Xia, G. Exploring the response of net primary productivity variations to urban expansion and climate change: A scenario analysis for Guangdong Province in China. J. Environ. Manag. 2015, 150, 92-102. [CrossRef] [PubMed]

27. Lu, C.; Wu, Y.; Shen, Q.; Wang, H. Driving force of urban growth and regional planning: A case study of China's Guangdong Province. Habitat Int. 2013, 40, 35-41. [CrossRef]

28. Zhong, B.; Peng, S.; Zhang, Q.; Ma, H.; Cao, S. Using an ecological economics approach to support the restoration of collapsing gullies in southern China. Land Use Policy 2013, 32, 119-124. [CrossRef]

29. Bendel, R.B.; Afifi, A.A. Comparison of stopping rules in forward "stepwise" regression. J. Am. Stat. Assoc. 1977, 72, 46-53.

30. Zhang, X.; Liao, C.; Li, J.; Sun, Q. Fractional vegetation cover estimation in arid and semi-arid environments using HJ-1 satellite hyperspectral data. Int. J. Appl. Earth Obs. Geoinf. 2013, 21, 506-512. [CrossRef]

31. Brunsdon, C.; Fotheringham, S.; Charlton, M. Geographically weighted regression. J. R. Stat. Soc. Ser. D 1998, 47, 431-443. [CrossRef]

32. Charlton, M.; Fotheringham, S.; Brunsdon, C. Geographically Weighted Regression; White Paper; National Centre for Geocomputation; National University of Ireland Maynooth: Maynooth, Ireland, 2009.

33. Huang, B.; Wu, B.; Barry, M. Geographically and temporally weighted regression for modeling spatio-temporal variation in house prices. Int. J. Geogr. Inf. Sci. 2010, 24, 383-401. [CrossRef]

34. Wang, Q.; Ni, J.; Tenhunen, J. Application of a geographically-weighted regression analysis to estimate net primary production of Chinese forest ecosystems. Glob. Ecol. Biogeogr. 2005, 14, 379-393. [CrossRef]

35. Kupfer, J.A.; Farris, C.A. Incorporating spatial non-stationarity of regression coefficients into predictive vegetation models. Landsc. Ecol. 2007, 22, 837-852. [CrossRef]

36. Da Silva, A.R.; Fotheringham, A.S. The multiple testing issue in geographically weighted regression. Geogr. Anal. 2016, 48, 233-247. [CrossRef]

37. Fotheringham, A.S.; Kelly, M.H.; Charlton, M. The demographic impacts of the Irish famine: Towards a greater geographical understanding. Trans. Inst. Br. Geogr. 2013, 38, 221-237. [CrossRef]

38. Li, C.; Kuang, Y.; Huang, N.; Zhang, C. The long-term relationship between population growth and vegetation cover: An empirical analysis based on the panel data of 21 cities in Guangdong province, China. Int. J. Environ. Res. Public Health 2013, 10, 660-677. [CrossRef] 
39. Han. Present status and conservation strategies of mangrove resource in Guangdong, P.R. china. J. For. Res. 2003, 14, 151-154. [CrossRef]

40. Chang, J.; Ren, H. The powerful image and the imagination of power: The 'new visual turn'of the CPC's propaganda strategy since its 18 th National Congress in 2012. Asian J. Commun. 2018, 28, 1-19. [CrossRef]

(C) 2020 by the authors. Licensee MDPI, Basel, Switzerland. This article is an open access article distributed under the terms and conditions of the Creative Commons Attribution (CC BY) license (http://creativecommons.org/licenses/by/4.0/). 